\title{
Importance of Thermal Stability Data to Avoid \\ Dangerous Reagents: Temozolomide Case Study
}

Jeffrey B. Sperry", Shane Stone, Michael Azuma, and Connor Barrett

Vertex Pharmaceuticals Incorporated, Process Chemistry, 50 Northern Avenue, Boston, MA

02210 


\begin{tabular}{|c|c|c|c|}
\hline \multicolumn{4}{|l|}{ Test Information } \\
\hline \multicolumn{2}{|l|}{ Test Name } & \multicolumn{2}{|c|}{ ARC-200303.3 } \\
\hline \multicolumn{2}{|l|}{ Test Date } & \multicolumn{2}{|c|}{ 3-Mar-20 } \\
\hline \multicolumn{2}{|l|}{ Test Equipment } & \multicolumn{2}{|c|}{ ARC 3} \\
\hline \multicolumn{4}{|l|}{ Sample Information } \\
\hline Chemical & \multicolumn{2}{|c|}{$\begin{array}{l}\text { Specific Heat } \\
\text { Capacity }(\mathrm{J} / \mathrm{g} / \mathrm{K})\end{array}$} & Mass (g) \\
\hline Temozolomide & \multicolumn{2}{|c|}{1.501} & 0.5716 \\
\hline \multicolumn{4}{|l|}{ Test Cell Information } \\
\hline \multicolumn{2}{|l|}{ Test Cell Material } & \multicolumn{2}{|c|}{ Stainless Steel } \\
\hline \multicolumn{2}{|l|}{ TC Clip Location } & \multicolumn{2}{|c|}{ Bottom } \\
\hline \multicolumn{2}{|l|}{ Mass of Test Cell (g) } & \multicolumn{2}{|c|}{12.9672} \\
\hline \multicolumn{2}{|c|}{$\begin{array}{l}\text { Specific Heat Capacity of Test } \\
\text { Cell }(\mathrm{J} / \mathrm{g} / \mathrm{K})\end{array}$} & \multicolumn{2}{|c|}{0.520} \\
\hline \multicolumn{2}{|c|}{ Mass of Aluminum Foil (g) } & \multicolumn{2}{|c|}{0.2734} \\
\hline \multicolumn{2}{|c|}{$\begin{array}{l}\text { Specific Heat Capacity of } \\
\text { Aluminum Foil }(\mathrm{J} / \mathrm{g} / \mathrm{K})\end{array}$} & \multicolumn{2}{|c|}{0.896} \\
\hline \multicolumn{2}{|l|}{ Test Cell Volume (ml) } & \multicolumn{2}{|l|}{9.5} \\
\hline \multicolumn{2}{|l|}{ System Volume (ml) } & \multicolumn{2}{|l|}{11.5} \\
\hline \multicolumn{2}{|c|}{ Test Cell Neck Diameter (in) } & \multicolumn{2}{|c|}{0.250} \\
\hline \multicolumn{2}{|c|}{ Test Cell Fittings Material } & \multicolumn{2}{|c|}{ Stainless Steel } \\
\hline Mass of Test Cell Fitting & gs (g) & 10.70 & \\
\hline Thermal Inertia & & 9.15 & \\
\hline Headspace & & Air & \\
\hline Operational Parameter & & & \\
\hline Mode of Operation & & HWS & \\
\hline Start Temperature $\left({ }^{\circ} \mathrm{C}\right)$ & & 50 & \\
\hline End Temperature $\left({ }^{\circ} \mathrm{C}\right)$ & & 400 & \\
\hline Temperature Step $\left({ }^{\circ} \mathrm{C}\right)$ & & 5 & \\
\hline Rate Sensitivity $\left({ }^{\circ} \mathrm{C} / \mathrm{min}\right.$ & & 0.02 & \\
\hline Cool Down Data & & & \\
\hline Final Sample Mass (g) & & 0.324 & \\
\hline Mass Loss (\%) & & 43.32 & \\
\hline Final Temperature $\left({ }^{\circ} \mathrm{C}\right)$ & & 23.4 & \\
\hline Final Pressure (psia) & & 67.2 & \\
\hline
\end{tabular}

Figure S-1. Test Parameters for HWS ARC Test for TMZ ( $\Phi=9.15)$ 


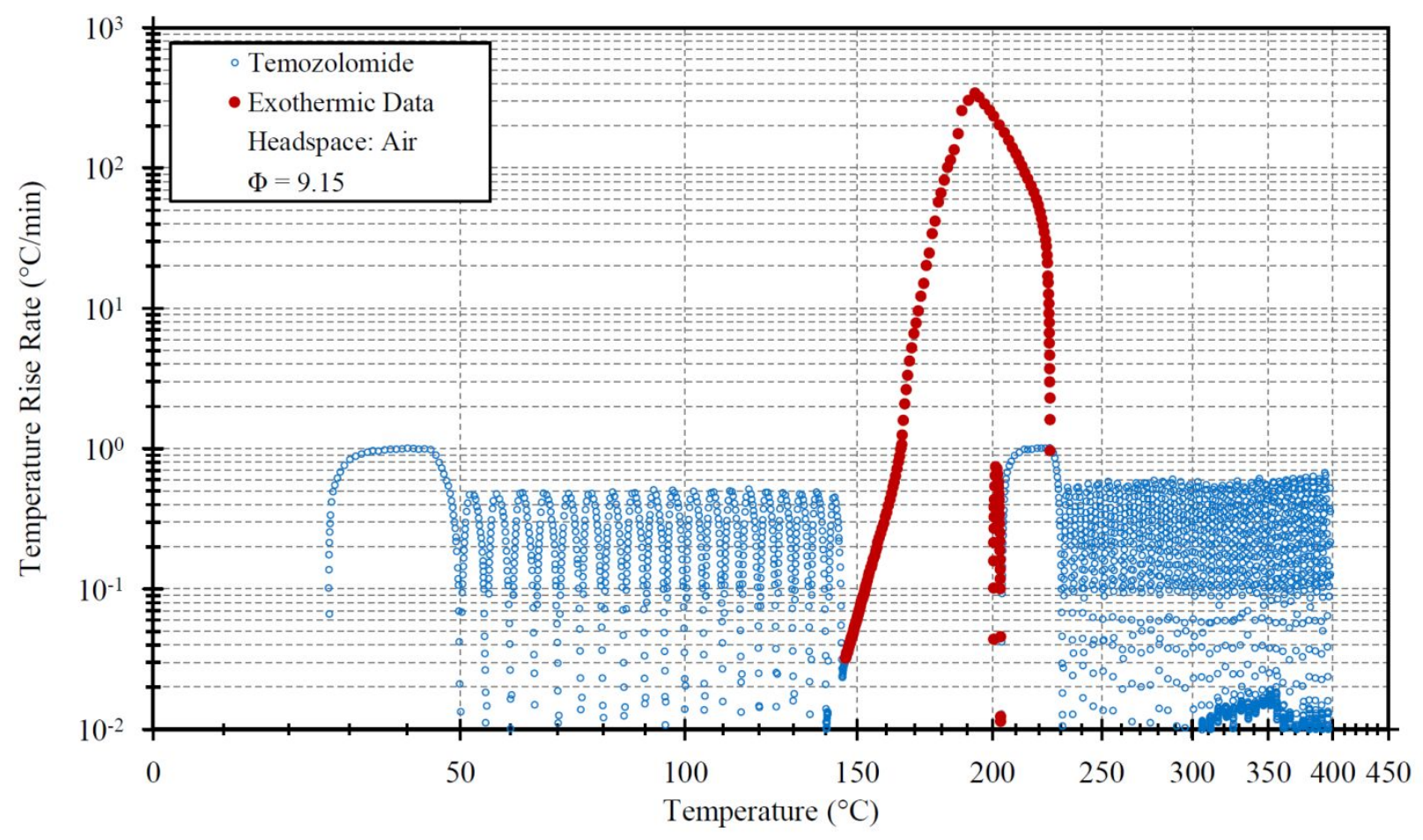

Figure S-1. Temperature Rise Rate vs. Temperature From TMZ ARC Experiment

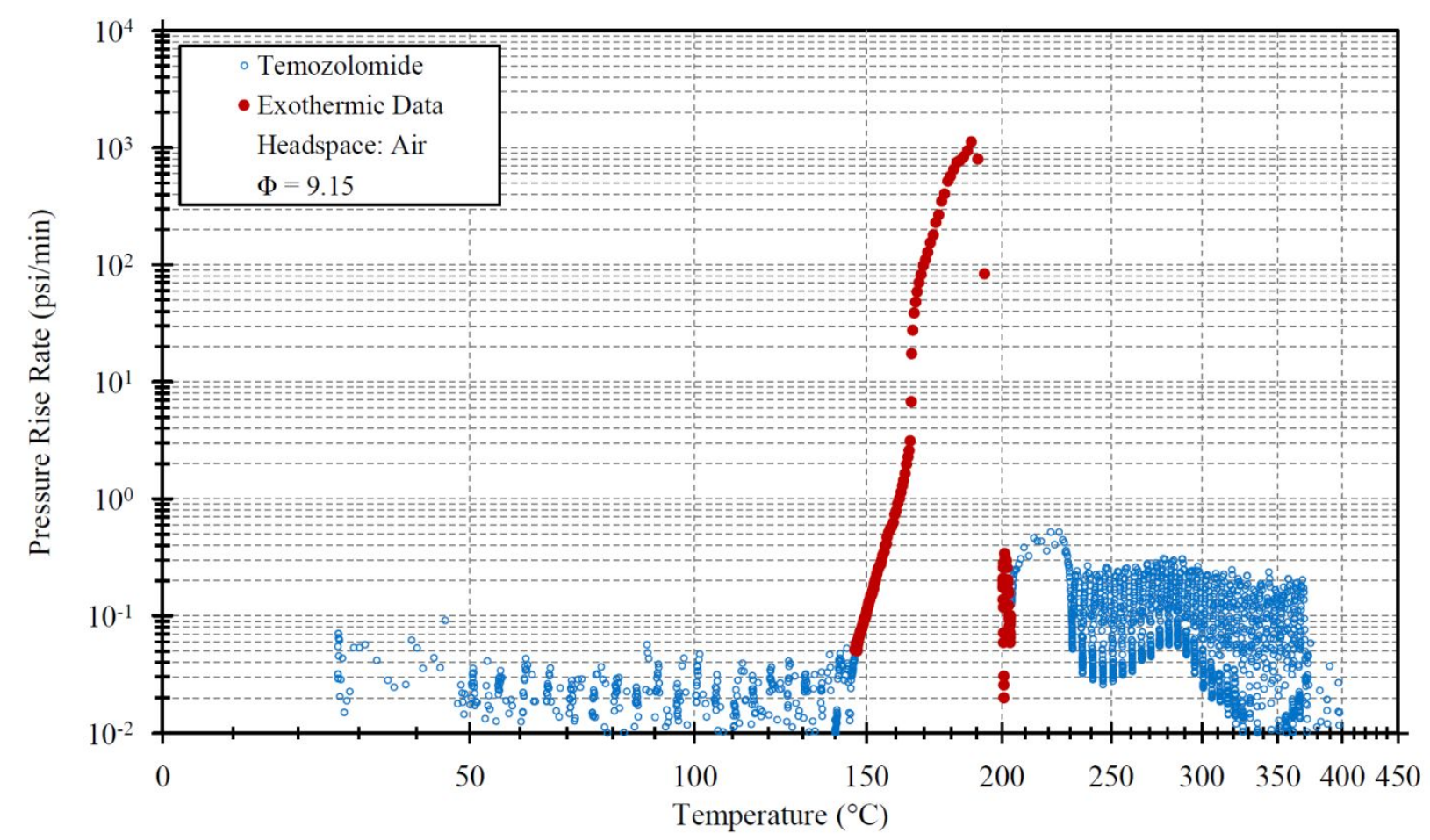

Figure S-2. Pressure Rise Rate vs. Temperature From TMZ ARC Experiment 


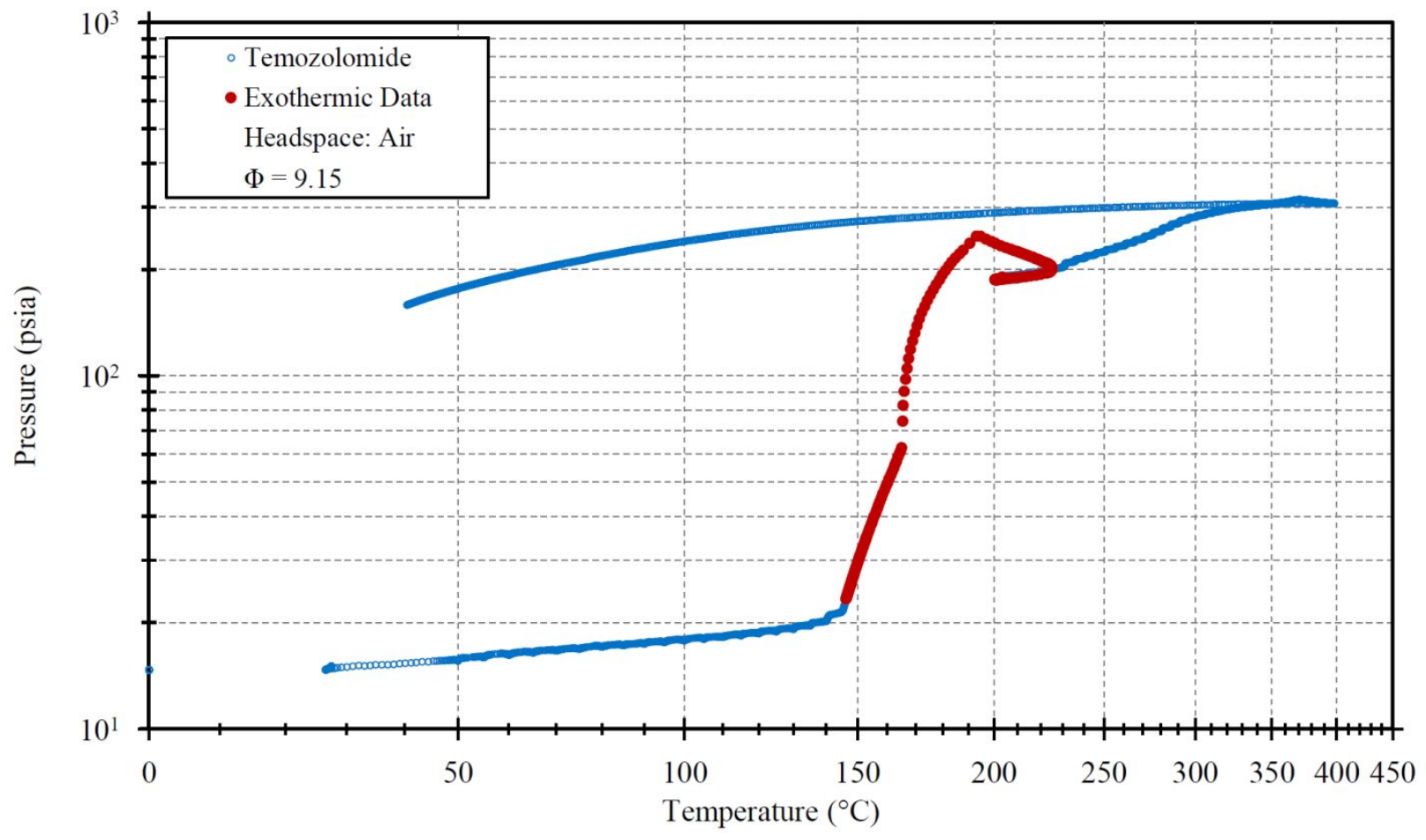

Figure S-3. Pressure vs. Temperature From TMZ ARC Experiment 
